\title{
Osteopontin Mediates Tumorigenic Transformation of a Preneoplastic Murine Cell Line by Suppressing Anoikis: An Arg-Gly-Asp-Dependent-Focal Adhesion Kinase-Caspase-8 Axis
}

\author{
Yu-Hua Hsieh, ${ }^{1}$ Henri van der Heyde, ${ }^{2}$ Eok-Soo Oh, ${ }^{3}$ Jun-Lin Guan, ${ }^{4}$ and Pi-Ling Chang ${ }^{1,5,6 *}$ \\ ${ }^{1}$ Department of Nutrition Sciences, 1720 2nd Avenue South, University of Alabama at Birmingham, Birmingham, \\ Alabama \\ ${ }^{2}$ La Jolla Infectious Disease Institute, San Diego, Califonia \\ ${ }^{3}$ Division of Molecular Life Sciences and Center for Cell Signaling Research, Department of Life Sciences, \\ Ewha Woman's University, Seoul, Korea \\ ${ }^{4}$ Division of Molecular Medicine and Genetics, Department of Internal Medicine, University of Michigan Medical School, \\ Ann Arbor, Michigan \\ ${ }^{5}$ Department of Dermatology, 1720 2nd Avenue South, University of Alabama at Birmingham, \\ Birmingham, Alabama \\ ${ }^{6}$ Department of Comprehensive Cancer Center, 1720 2nd Avenue South, University of Alabama at Birmingham, \\ Birmingham, Alabama
}

Osteopontin (OPN), an adhesive, matricellular glycoprotein, is a rate-limiting factor in tumor promotion of skin carcinogenesis. With a tumor promotion model, the JB6 Cl41.5a cell line, we have shown that suppressing 12-Otetradecanoylphorbol-13-acetate (TPA)-induced OPN expression markedly inhibits TPA-induced colony formation in soft agar, an assay indicative of tumorigenic transformation. Further, the addition of exogenous OPN promotes colony formation of these cells. These findings support a function of OPN in mediating TPA-induced neoplastic transformation of JB6 cells. In regard to the mechanism of action by OPN, we hypothesized that, for JB6 cells grown in soft-agar, secreted OPN induced by TPA stimulates cell proliferation and/or prevents anoikis to facilitate TPA-induced colony formation. Analyses of cell cycle and cyclin D1 expression, and direct cell counting of JB6 cells treated with OPN indicate that OPN does not stimulate cell proliferation relative to non-treated controls. Instead, at $24 \mathrm{~h}, \mathrm{OPN}$ decreases anoikis by $41 \%$, as assessed by annexin $\vee$ assays. Further, in suspended cells OPN suppresses caspase-8 activation, which is mediated specifically through its RGD-cell binding motif that transduces signals through integrin receptors. Transfection studies with wild-type and mutant focal adhesion kinases (FAK) and Western blot analyses suggest that OPN suppression of caspase-8 activation is mediated through phosphorylation of FAK at $\mathrm{Tyr}^{861}$. In summary, these studies indicate that induced OPN is a microenvironment modulator that facilitates tumorigenic transformation of JB6 cells by inhibiting anoikis through its RGDdependent suppression of caspase-8 activity, which is mediated in part through the activation of FAK at Tyr ${ }^{861}$. (c) 2013 Wiley Periodicals, Inc.

Key words: JB6 cells; apoptosis, phorbol ester, over-agar assay

\section{INTRODUCTION}

Tumor promotion occurs when initiated cells, possessing permanent genetic alterations, acquire proliferative capacity and form benign tumors. This stage is the first-rate limiting step in multistage carcinogenesis, since initiated cells may die or remain dormant, surviving in a favorable microenvironment for an extended period prior to transformation. We have shown that induced expression of a matricellular protein, osteopontin (OPN) is an important microenvironment modulator in tumor promotion that facilitates papilloma development, likely through enhancing the survival of initiated basal keratinocytes [1].

OPN is a secreted, adhesive glycoprotein consisting of three main conserved motifs: a consecutive
Abbreviations OPN, osteopontin; RGD, Arg-Gly-Asp; DRYLKFR, Asp-Arg-Tyr-Leu-Lys-Phe-Arg; JB6, JB6 Cl41.5a cell line; TPA, 12-Odecanoylphorbol-13-acetate; FN, fibronectin; VN, vitronectin; FAK, focal adhesion kinase; HI-FBS, heat-inactivated fetal bovine serum; rOPN, recombinant rat OPN; DMSO, dimethylsulfoxide; ELISA enzyme-linked immunosorbant assay; SD, standard deviation; PS, phosphatidylserine; BSA, bovine serum albumin; PI-3 kinase, phosphatidylinositol 3-kinase

Grant sponsor: NCl R01 (P.-L.C.) CA90920 R01 CA137091; Grant sponsor: P. L. Chang Research, Department of Nutrition Sciences

*Correspondence to: Pi-Ling Chang, 1675 University Boulevard, University of Alabama at Birmingham, Birmingham, AL 35295-3360. Received 4 March 2013; Revised 16 October 2013; Accepted 23 October 2013

DOI 10.1002/mc.22108

Published online 19 November 2013 in Wiley Online Library (wileyonlinelibrary.com). 
sequence of 8-10 aspartic acid residues shown to bind calcium or hydroxyapatite; an Arg-Gly-Asp (RGD) sequence that binds integrins; and an Asp-Arg-TyrLeu-Lys-Phe-Arg (DRYLKFR) sequence that interacts with the hyaluronic acid receptor, CD44s, or it variants. The primary structure of OPN reflects its functions in mineralization, prevention of calcification, chemotaxis, cell signaling, and cell survival [24]. The expression of OPN is induced during pathological conditions such as cancer, and it is thought to facilitate tumorigenesis, cancer progression, and metastasis [1,5-7]. In the present investigation, we used the "initiated" transformation-sensitive $(\mathrm{P}+)$, epidermal-like cells to elucidate the mechanism by which induced OPN enhances tumorigenic transformation.

The promotable murine JB6 Cl41.5a cell line (JB6), established by Colburn et al. [8], has been widely used as a model for studies of tumor promotion. These cells are stable in that, over several passages, they retain their morphology and have minimal capacity to form colonies in soft agar. However, upon treatment with the skin tumor promoter, 12-O-decanoylphorbol-13acetate (TPA), they become transformed, as assessed by their capacity to form colonies on soft agar, a property that correlates with tumorigenic transformation in vivo [9]. Studies using these promotable cells have identified proto-oncogenes, AP-1 and ornithine decarboxylase $[10,11]$, and the tumor suppressor Pdcd4 [12], which are predictive of promoting or inhibiting tumor promotion in intact animals [13-16].

We have shown that OPN is also a mediator of TPAinduced transformation of JB6 cells [17]. These cells normally express minimal levels of OPN, but TPA markedly stimulates its mRNA, which was originally named 2ar by Denhardt and colleagues [18]. A steadystate level of OPN mRNA is induced by TPA as early as $2-4 \mathrm{~h}$, peaks at $16 \mathrm{~h}$, and decreases slightly by $24 \mathrm{~h}$. This increase at the mRNA level correlates with the increase in the level of secreted OPN $[19,20]$. Furthermore, if the media is not limiting, TPAinduced expression of OPN can persist for at least $4 \mathrm{~d}$. Because previous studies have shown that the induction of colony formation requires the presence of TPA for at least $4 \mathrm{~d}$ [21], the continuous presence of secreted OPN suggests that OPN may function as an autocrine factor mediating TPA-induced colony formation in soft-agar. Indeed, TPA-treated JB6 cells exhibit increase adhesion to plate-bound OPN (likely through $\alpha v \beta 5$ integrin) and concomitantly, decrease adhesion to fibronectin (FN) and vitronectin (VN) [22]. Furthermore, OPN stimulates colony formation of JB6 cells and that suppression of OPN expression compromises TPA-induced transformation of JB6 cells [17].

Here, we determine mechanism(s) by which induced OPN facilitates colony formation of JB6 cells. Our data indicate that OPN does not stimulate proliferation of JB6 cells, but rather enhances the survival of cells suspended on agar, an assay used to mimic early time points of soft-agar assays [23]. Furthermore, the capacity of OPN to delay anoikis of JB6 cells by suppressing caspase- 8 activity is mediated through its RGD-cell binding motif and, in part, the phosphorylation of focal adhesion kinase (FAK) at $\mathrm{Tyr}^{861}$.

\section{MATERIALS AND METHODS}

\section{Cell Line}

Mouse JB6 Cl41.5a (JB6) cells, which are preneoplastic and epidermal-like, were generously provided by Dr. N. Colburn of the National Cancer Institute, Frederick, MD [24]. Cells were maintained in Eagles Minimum Essential Medium (MEM) supplemented with $5 \%$ heat-inactivated fetal bovine serum (HI-FBS) (Hyclone, Logan, UT), 4 mM glutamine (Irvine Scientific, Santa Ana, CA), 50 units/ml of penicillin, $50 \mu \mathrm{g} /$ $\mathrm{ml}$ of streptomycin, and $0.125 \mu \mathrm{g} / \mathrm{ml}$ of amphotericin B (Irvine Scientific). To avoid mycoplasma contamination, cells were sub-cultured prior to confluence and checked monthly by use of DNA fluorochrome staining [25]. Cell numbers were determined by use of a hemocytometer.

DNA Analyses by Flow Cytometry and Cell Proliferation Analyses

JB6 cells were seeded at equal density $(25,000$ cells/ $\mathrm{cm}^{2}$ ) in 60-mm dishes and after $24 \mathrm{~h}$, treated with PBS and/or $3 \mu \mathrm{g} / \mathrm{ml}$ of recombinant rat OPN (rOPN), or $0.001 \%$ dimethylsulfoxide (DMSO), and/or $10 \mathrm{ng} / \mathrm{ml}$ (16.2 nM) of TPA (duplicate or triplicate dishes/ treatment) with no media change. rOPN was purified as previously described [26]. Only purified batches with low endotoxin $(<1 \mathrm{ng}$ in $45 \mu \mathrm{g}$ of rOPN) were used. Cells were harvested at $25 \mathrm{~h}$ after treatment and fixed with $100 \%$ ethanol. DNA analyses were performed according to a modified protocol [27]. Fixed suspended cells were treated with $200 \mu \mathrm{g} / \mathrm{ml}$ of RNase, stained with $20 \mu \mathrm{g} / \mathrm{ml}$ of propidium iodide (Sigma, St Louis, MO), and incubated for $30 \mathrm{~min}$ prior to flow cytometry analyses (Becton Dickenson FACS Calibur, BD Biosciences, San Jose, CA). DNA contents in various stages of cell cycle were determined by ModFitLT V3.3.11 (Mac).

For cell proliferation analyses, similar experiments were performed, except that cells were seeded in 24 wells (triplicate wells per treatment) and incubated for $48 \mathrm{~h}$ with rOPN or PBS as control in the presence of growth media. Cells were trypsinized and counted by use of a hemocytometer.

\section{Over-Agar Assay}

JB6 cells were trypsinized and suspended with or without drugs (see below for further details) in MEM containing 5\% HI-FBS on $0.7 \%$ agar. Cells were then harvested at various time points for determination of 
secreted OPN by enzyme-linked immunosorbant assay (ELISA), annexin $\mathrm{V}$ and caspase activity, and for Western blot analyses. All over-agar assays were performed in the presence of 5\% HI-FBS, unless otherwise stated.

\section{ELISA for Secreted OPN}

For analyses of secreted OPN from adherent JB6 cells, cells were seeded at equal density in 24-well culture dish. After $24 \mathrm{~h}$, cells were not treated or treated with $10 \mathrm{ng} / \mathrm{ml}$ of TPA or $0.001 \%$ DMSO (control). Likewise, suspended cells in over-agar in 24-well cultured dishes were treated as described above. Conditioned media after $24 \mathrm{~h}$ of treatment were collected and analyzed for secreted OPN with ELISA (Assay Design, Ann Arbor, MI). The number of cells of each treatment was determined with a hemocytometer. The secreted OPN concentration was normalized to 10,000 cells.

\section{Anoikis Analyses by Annexin $\mathrm{V}$ Labeling}

Cells were seeded at 9,000 cells $/ \mathrm{cm}^{2}$ in $150 \times 25$ $\mathrm{mm}$ tissue culture plates. After $2 \mathrm{~d}$, cells were trypsinized and re-suspended in $10 \mathrm{ml}$ of media with PBS and/or $4 \mu \mathrm{g} / \mathrm{ml}$ of rOPN, or $0.001 \%$ of DMSO and/or $10 \mathrm{ng} / \mathrm{ml}$ of TPA and layered on $0.7 \%$ agar-coated $150 \times 25$-mm dishes. After $24 \mathrm{~h}$, cells were harvested, rinsed with PBS, and re-suspended in $500 \mu \mathrm{l}$ of binding buffer from an Annexin V-FITC Apoptosis Detection Kit (BD Pharmingen $^{\mathrm{TM}}$, San Jose, CA). Resuspended cells from each sample were placed in four tubes containing $100 \mu \mathrm{l}$ per tube. Cells in each of the tubes were either labeled or not labeled with Annexin V-FITC or propidium iodide, or both, and analyzed by flow cytometry. The experiment was repeated two more times.

Caspase Activity Assay With RGD-Cell Binding or CD44Binding Peptides, Wortmannin, or FAK Inhibitor 14

To screen for the various caspases activated upon anoikis of JB6 cells, the ApoAlert Caspase Profiling Plate was used according to manufacturer's instructions (Clontech, Mountain View, CA). Briefly, cells $\left(2 \times 10^{6}\right)$ layered on agar were treated with or without rOPN for designated times prior to harvest. Pelleted cells were lysed in lysis buffer (0.1 M Hepes, pH 7.4, containing $2 \mathrm{mM}$ dithiothrietol, and $0.1 \%$ Chaps) and incubated with $50 \mu \mathrm{l}$ of $50 \mathrm{mM}$ fluorogenic caspase-8 peptide substrate, Ac-IETD-AFC (7-amino-4-trifluoromethylcoumarin) for $2 \mathrm{~h}$ at $37^{\circ} \mathrm{C}$. Protein concentration was determined by bicinchoninic acid method. The release of AFC was measured with excitation at $400 \mathrm{~nm}$ and emission at $505 \mathrm{~nm}$ using a fluorescence spectrophotometer. For analyses of caspase- 9 and caspase- 3 activities, similar experiments were performed using substrates Ac-LEHDAMC (7-amino-4-methoxy coumarin) and Ac-DEVDAFC, respectively. In assessing caspase-3 activity, an inhibitor to caspase-3 activity $(10 \mu \mathrm{M})$ was also included. Data are presented as fold-increase of caspase activity relative to that of 0 -h time point.

Subsequent analyses on the effects of rOPN in suppressing caspase- 8 activity of suspended JB6 cells were performed using the caspase- 8 substrate, AcLETD-AFC (Bachem, Torrance, CA). For studies involving wortmannin (Sigma) and FAK inhibitor 14 (Santa Cruz Biotechnology, Santa Cruz, CA), adherent JB6 cells were pre-incubated with drugs for $30 \mathrm{~min}$ and $1 \mathrm{~h}$, respectively, prior to suspension for FAK and/or caspase-8 analyses. For studies involving RGD-cell binding (GRGDSL) or CD44-binding (DRYLKFRI) peptides (American Peptide Company, Sunnyvale, CA), suspended cells are incubated with peptides (GRGDSL, GRGESL or DRYLKFRI) with or without rOPN for $1 \mathrm{~h}$ prior to harvest. Experiments were repeated at least two more times.

\section{Immunoprecipitation and Western Blot Analyses}

The suspended cells were collected after incubation at the times as the indicated. The pelleted cells were lysed by the RIPA buffer containing protease inhibitors (Roche, Indianapolis, IN) and sodium orthovanadate, a phosphatase inhibitor (Sigma). After centrifugation of the preparations, the protein contents in the supernatants were quantified by the bicinconinic acid method (Thermo Fisher Scientific Inc, Waltham, MA), and equal amounts of protein were incubated with the polyclonal anti-FAK (Santa Cruz Biotechnology) and Dynabeads Protein A (Invitrogen, Grand Island, NY) at $4^{\circ} \mathrm{C}$ overnight. After incubation, cells lysates were centrifuged and washed. The pellets were collected and subjected to $7 \%$ SDS-polyacrylamide gel electrophoresis. For Western blot analyses, the proteins on the gel were transferred onto PVDF membranes and probed with antibodies to phospho-Tyr ${ }^{397}$ of FAK, FAK (Santa Cruz Biotechnology) and phospho-Tyr ${ }^{861}$ or phospho$\mathrm{Tyr}^{925}$ of FAK (GenScript, Piscataway, NJ). Primary antibody-binding sites were detected using secondary antibody coupled to horse-radish peroxidase. Bands were visualized by chemiluminescence (Luminata Forte, EMD Millipore, Billerica, MA) using Blue-X ray films. For cyclin D1 analyses, adherent cells were treated with rOPN $(3 \mu \mathrm{g} / \mathrm{ml})$ or PBS for $42 \mathrm{~h}$ and cell lysates were harvested for Western blot analyses using cyclin D1 antibody (Santa Cruz Biotechnology).

\section{Cell Transfection With Mammalian Expression Vectors of} Wild-Type and Mutant FAK

JB6 cells were seeded and transfected at approximately $70 \%$ confluence with the plasmids at the indicated times using Lipofectamine ${ }^{\mathrm{TM}}$ (Invitrogen) according to the manufacture's instructions. The medium was changed after $5 \mathrm{~h}$ of incubation. The plasmids transfected were wild-type FAK in pKH3 [28], mutant FAK-Y861F (Tyr ${ }^{861}$ changed to Phe ${ }^{861}$ ) in pRC/ CMV [29], mutant FAK-Y925F (Tyr ${ }^{925}$ changed to $\mathrm{Phe}^{925}$ ) in pcDNA3 [30], and vector only. To verify the 
expression of WT-FAK and mutant FAKs Western blot analyses were performed.

\section{Statistical Analyses}

Data were expressed as mean \pm standard deviation (SD). $t$-Test was used for comparison between groups. $P$ values $<0.05$ were statistically significant. All the analyses were performed using the Statistical Analysis Program in SigmaPlot 11.0 or in Microsoft Office Excel 2007.

\section{RESULTS}

We have previously reported that OPN mediates TPA-induced tumorigenic transformation or colony formation of JB6 cells [17] and addition of exogenous OPN promotes colony formation of these cells. Here, we addressed whether the OPN-enhanced colony formation of these cells is accomplished by stimulation of cell proliferation or by enhancement of cell survival. Further, the molecular mechanisms involved were determined. Adherent JB6 cells express and secrete minimal levels of OPN [17]; only upon treatment with TPA do they markedly express OPN. To avoid the confounding mitogenic and other effects of TPA on JB6 cells, assays were performed with addition of exogenous rOPN.

\section{OPN Does Not Stimulate Proliferation of JB6 Cells}

To determine whether OPN stimulates cell proliferation, cell cycle analyses, direct cell counting and cyclin D1 expression were performed on cells attached to culture dishes in the presence of soluble rOPN. For cell cycle analyses, cells were treated for $25 \mathrm{~h}$ with $3 \mu \mathrm{g} / \mathrm{ml}$ of rOPN, $10 \mathrm{ng} / \mathrm{ml}$ of TPA as positive control, or their corresponding negative controls, PBS and $0.001 \%$ of DMSO, respectively. DNA contents at different phases of cell cycle were measured by flow cytometry. rOPN did not stimulate an increase in the S-phase of the cell cycle and nor were any differences in $\mathrm{G} 0 / \mathrm{G} 1$ and $\mathrm{G} 2 / \mathrm{M}$ cell cycle phases observed relative to PBS-treated control cells (Figure 1A, left panel, see actual flow cytometry data, S1, S1-continued). In contrast, TPA-treated cells showed an increase in DNA content in the $S$-phase and a decrease in numbers of cells in the G0/G1 and G2/M phases of the cell cycle (Figure 1A, right panel, see actual flow cytometry data, S2).

Further analyses of whether OPN stimulates cell proliferation, performed by direct cell counting with a hemocytometer, also indicated that JB6 cells treated with soluble rOPN for $48 \mathrm{~h}$ did not increase in numbers relative to control cells (Figure 1B). In contrast to OPN, TPA stimulates proliferation of JB6 cells by $48 \mathrm{~h}$ [31]. Further, Western blot analyses showed that rOPN did not cause an increase in cyclin D1 expression (data not shown). Collectively, these findings indicate that soluble rOPN does not stimulate cell proliferation of JB6 cells.

\section{OPN Prevents Anoikis of JB6 Cells}

To determine if OPN prevents anoikis of JB6 cells in soft agar, we used the over-agar assay, which correlates with tumorigenic transformation in vitro [23]. In this assay, cells were suspended in the presence of serum to mimic the condition of softagar assay and on $0.7 \%$ agar to allow for the recovery of cells for biochemical analyses. Suspended cells were treated with $4 \mu \mathrm{g} / \mathrm{ml}$ of rOPN or PBS for $24 \mathrm{~h}$ and analyzed for cell surface expression of phosphatidylserine (PS), an early marker for apoptosis. Cells were incubated with annexin V, which binds to PS, to detect early-stage apoptotic cells, propidium iodide to detect dead cells, or both annexin $\mathrm{V}$ with PI propidium iodide to detect necrotic or latestage apoptotic cells; flow cytometry was used for analysis. After $24 \mathrm{~h}$, rOPN suppressed by $41 \%$ (annexin $\mathrm{V}$ binding only) the number of cells undergoing anoikis relative to those treated with PBS (Table 1).

In our analyses of cells in suspension, one may argue that the overall percentage of apoptotic cells in suspended JB6 cells is too low as compared to other published studies. We attribute this to two main reasons. Firstly, the methodologies of analysis for apoptotic cells may differ, such as the application of Hoechst 33528 nuclear staining versus the annexin $\mathrm{V}$ assay. Hoechst 33528 staining scores most of the late-stage apoptotic cells, which are usually much higher [32], while the annexin $\mathrm{V}$ assay separates the early-stage apoptotic cells (annexin V only) from that of the late-stage apoptotic/necrotic cells (annexin V+PI). In Table 1, the higher percentages of late-stage apoptotic/necrotic cells of JB6 cells suspended for $24 \mathrm{~h}$ in PBS and OPN likely correspond to those cells stained with Hoechst 33528. Secondly, the presence or lack of serum can dictate the number of apoptotic cells in suspension. In the present study, cells were suspended in 5\% HIFBS resulting in lower percent of early-stage apoptotic cells (Table 1) as compared to studies where cells were pre-incubated for 24 or $48 \mathrm{~h}$ in serum-free conditions [33]. Therefore, the components in the serum can promote the survival of suspended cells. Despite the presence of serum, we observed that the addition of rOPN can further prevent anoikis of suspended JB6 cells when compared to those treated with PBS only (Table 1).

\section{Suspended JB6 Cells Secrete Minimal Amounts of OPN}

To determine if the prevention of anoikis by OPN is only from the exogenous rOPN and not from endogenous synthesis of OPN while cells are in suspension, level of secreted OPN in conditioned media at $24 \mathrm{~h}$ was measured for suspended JB6 cells not treated or treated with TPA as a positive control or DMSO as vehicle control. Suspended cells secreted minimal levels of OPN; only in the presence of TPA 
A
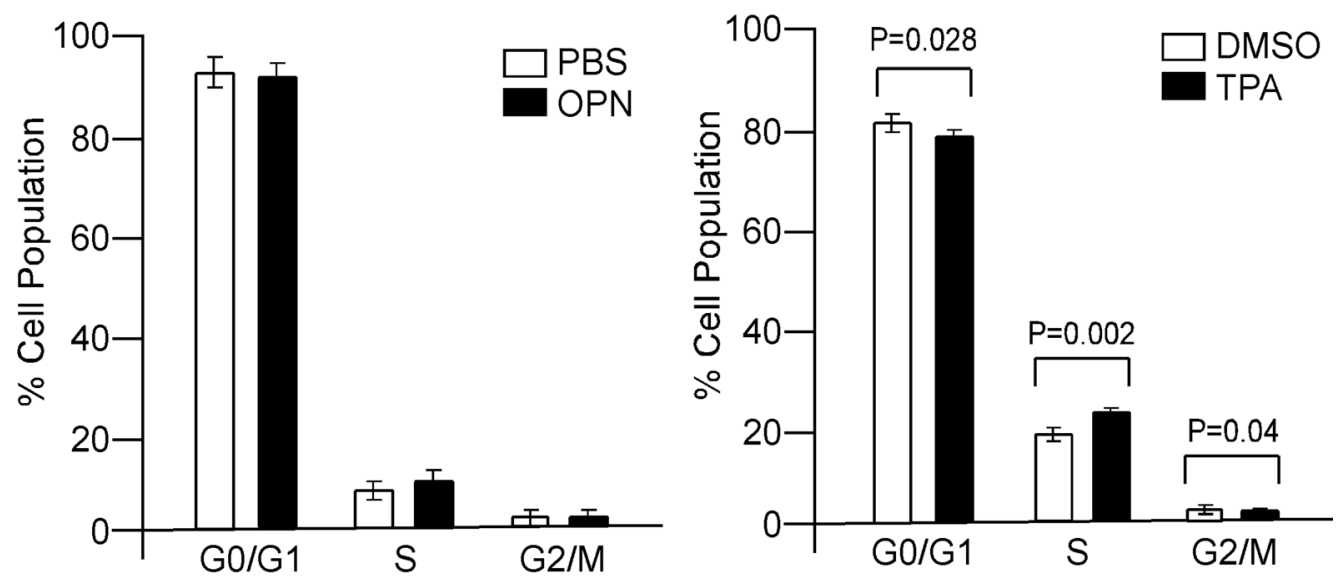

B

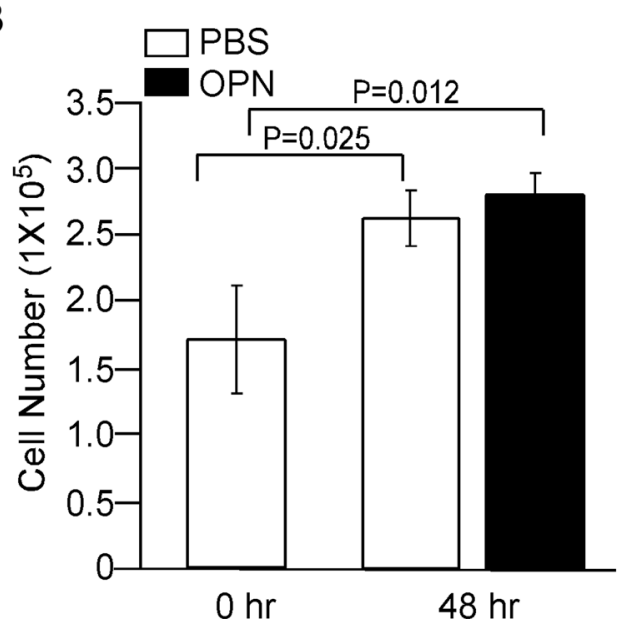

Figure 1. OPN does not stimulate cell proliferation of JB6 Cl41.5a cells. (A) Cell cycle analyses of JB6 cells treated with OPN or TPA. Cells in growth media were treated with $3 \mu \mathrm{g} / \mathrm{ml}$ of rOPN $(n=8)$ and/or PBS $(n=6)$ or with $10 \mathrm{ng} /$ $\mathrm{ml}$ of TPA $(n=5)$ and/or $0.0001 \%$ DMSO $(n=5)$ for $25 \mathrm{~h}$ prior to analyses by flow cytometry. See supplemental data, Figures S1, S1-continued, and S2. (B) Cell proliferation analyses of JB6 cells treated with rOPN. Soluble rOPN (1.4 $\mu \mathrm{g} /$ $\mathrm{ml}$ ) or $1 \% \mathrm{BSA}$ as control were added to adherent JB6 cells for $48 \mathrm{~h}$. Cells were collected by trypsinization and counted by use of a hemocytometer, $n=3 /$ treatment. Comparisons between groups were analyzed by $t$-test in this figure and the rest of the other figures.

were substantial amounts (13-fold) of OPN present (Table 2). Thus, the observed prevention of anoikis by exogenous OPN (Table 1) is not confounded by the minimal synthesis of endogenous OPN when cells are in suspension.
Anoikis of JB6 Cells Is Mediated Through Caspase-8, -9, and -3

To determine the mechanisms by which OPN delays anoikis, activities of the various caspases involved in the anoikis of JB6 cells were first evaluated

Table 1. Annexin V Analysis by Flow Cytometry of Suspended JB6 Cells Treated With OPN for $24 \mathrm{~h}$

\begin{tabular}{lccr}
\hline Treatment & PBS-Susp & OPN-Susp & No tx-Ad \\
\hline Viable cells (\%), No staining for Annexin V + PI & $62.35 \pm 6.50$ & $70.85 \pm 6.40$ & $90.56 \pm 3.36$ \\
Early-stage Apoptotic cells (\%), Annexin V only & $5.89 \pm 0.73$ & $3.50 \pm 0.21^{*}$ & $1.18 \pm 0.38$ \\
Late-stage apoptotic/necrotic cells (\%), Annexin V+PI & $20.80 \pm 0.03$ & $16.87 \pm 2.50^{*}$ & $6.83 \pm 3.70$ \\
Dead cells (\%), Pl only & $10.97 \pm 7.2$ & $8.76 \pm 4.00$ & $1.43 \pm 0.83$ \\
\hline
\end{tabular}

Susp, suspended cells; No Tx, no treatment; Ad, adherent cells; PI, propidium iodide.

$\mathrm{N}=3$ per group.

${ }^{*} P<0.05$. 
Table 2. ELISA of Secreted OPN Protein in Adherent and Suspended JB6 Cells

\begin{tabular}{lccr}
\hline Treatment & None & DMSO & TPA \\
\hline Adherent cells & $0.665 \pm 0.31^{*}$ & $1.11 \pm 0.61$ & $207.9 \pm 15.2$ \\
Suspended cells & $0.608 \pm 0.12$ & $0.50 \pm 0.13$ & $8.2 \pm 1.59^{* *}$ \\
\hline
\end{tabular}

All samples, $\mathrm{n}=3$, except for adherent cells in DMSO, $\mathrm{n}=2$.

${ }^{*} \mathrm{ng} / 10,000$ cells \pm standard deviation.

${ }^{* *} P=0.001$ relative to no treatment and DMSO-treated suspended cells.

with ApoAlert Caspase Profiling Plate. JB6 cells in suspension triggered the activation of caspases- $8,-9$ and -3 , which peaked as early as 1,3 , and $18 \mathrm{~h}$, respectively (Figure $2 \mathrm{~A}-\mathrm{C}$ ), but not caspase- 2 (data not shown). For caspase- 8 additional studies were performed to assess its activity with specific peptide substrate not using the ApoAlert Caspase Profiling Plate. These findings indicate that anoikis of JB6 cells initiates a cascade of caspase activation, with caspase8 being the first to be activated, followed by caspases- 9 and -3 .

Suppression of Caspase-8 Activity/Anoikis of JB6 Cells by OPN Is Not Dose-Dependent

To determine if anoikis suppressed by OPN is dosedependent, suspended cells were incubated with increasing concentrations of rOPN, and caspase- 8 activation was assessed. rOPN suppression of caspase8 activity was not dose-dependent. rOPN at low dose $(0.4 \mu \mathrm{g} / \mathrm{ml})$ did not suppress caspase- 8 activity relative to that of control cells. Instead a significant suppression of caspase- 8 activity relative to that if control cells was observed at $1.4 \mu \mathrm{g} / \mathrm{ml}$ of OPN; while, no further increase in suppression of caspase- 8 activity was observed at higher OPN concentration, $5 \mu \mathrm{g} / \mathrm{ml}$ (Figure 2D). These findings indicate that for JB6 cells in suspension, there is a threshold amount of exogenous OPN required to initiate the suppression of caspase- 8 activity and/or anoikis and that its effect is receptor mediated.

In previous experiments (Figure 1 and Table 1), which involved longer incubation times (24-48 h), higher concentrations of OPN $(3-4 \mu \mathrm{g} / \mathrm{ml})$ were used, because they were based on the concentration used in the previous soft-agar assays [17]. Since higher concentration of OPN beyond $1.4 \mu \mathrm{g} / \mathrm{ml}$ did not further suppress caspase-8 activity in over-agar assays, subsequent experiments were performed at this concentration.

Suppression of Caspase-8 Activity of JB6 Cells by OPN Is Mediated Through Its RGD Motif

To establish if suppression of caspase- 8 activation by OPN is mediated through its integrin-binding (RGD) or its putative CD44-binding (DRYLKFRI) motif, cells in suspension were incubated with $1 \mu \mathrm{M}$ of GRGDSL, GRGESL (a nonspecific peptide), or DRYLKFRI with or without rOPN $(1.4 \mu \mathrm{g} / \mathrm{ml})$. To ensure competitive binding of these peptides with the cell surface receptors, the amounts of the peptides present $(7.0 \mathrm{nmol})$ were greater than that of OPN $(0.27 \mathrm{nmol})$. Incubation of suspended JB6 cells with the GRGDSL peptide for $1 \mathrm{~h}$ suppressed caspase- 8 activity as effectively as for cells treated with only rOPN, relative to values for control cells (CT) with $1 \%$ bovine serum albumin (BSA) (Figure 2E). The addition of rOPN to cells with the GRGDSL peptide did not further suppress caspase- 8 activation relative to values for cells incubated with GRGDSL only. In contrast to the GRGDSL peptide, the non-specific GRGESL peptide did not suppress caspase- 8 activity relative to that for untreated control cells; instead, only in the presence of rOPN was caspase- 8 activity suppressed. Thus, rOPN suppression of caspase- 8 activation is mediated in part through its RGD motif.

Further, rOPN suppression of caspase- 8 activation is not mediated through the CD44 receptor, because the DRYLKFRI peptide did not suppress caspase- 8 activity relative to untreated cells. Nevertheless, rOPN suppressed this activity relative to that in cells exposed to the DRYLKFRI peptide (Figure 2E).

OPN Suppression of Caspase-8 Activity Is Not Mediated by the Activation of Phosphatidylinositol 3-Kinase (PI-3 Kinase)

Since OPN-enhanced survival of adherent cells can be mediated by the phosphatidylinositol 3-kinase (PI3 kinase)/Akt signaling pathway through interaction with the CD44 receptor [34], this possibility was investigated for suspended JB6 cells. Adherent JB6 cells were pre-treated with the PI-3 kinase inhibitor, wortmannin, at 0,25 , and $50 \mathrm{nM}$ for $30 \mathrm{~min}$ prior to placing the cells in suspension in the presence of wortmannin, rOPN, or BSA. Inhibition of PI-3 kinase by wortmannin increased the activity of caspase- 8 of suspended cells in a dose-dependent manner (Figure 3A). However, addition of rOPN suppressed the activity of caspase- 8 in cells treated with $50 \mathrm{nM}$ of wortmannin, suggesting that this suppression is independent of PI-3 kinase activity.

OPN Suppression of Caspase-8 Activity Is Mediated Through FAK Activation

FAK is a non-receptor tyrosine kinase protein involved in development and processes such as cell adhesion, migration, and survival [35]. Prolonging cell survival through the binding of matrix proteins to integrin receptors is mediated through the activation 
A

Caspase-8 Activity

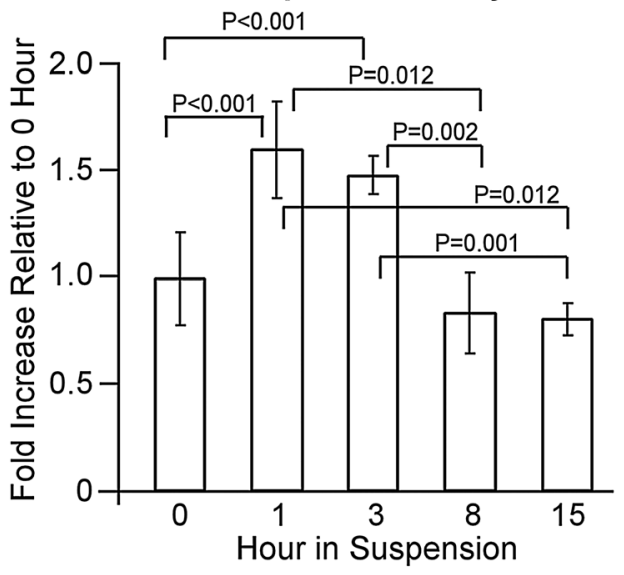

\section{B}

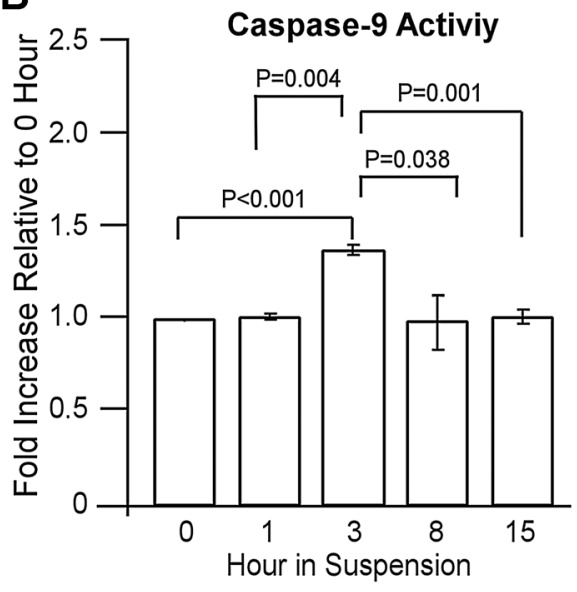

D Caspase-8 Activity

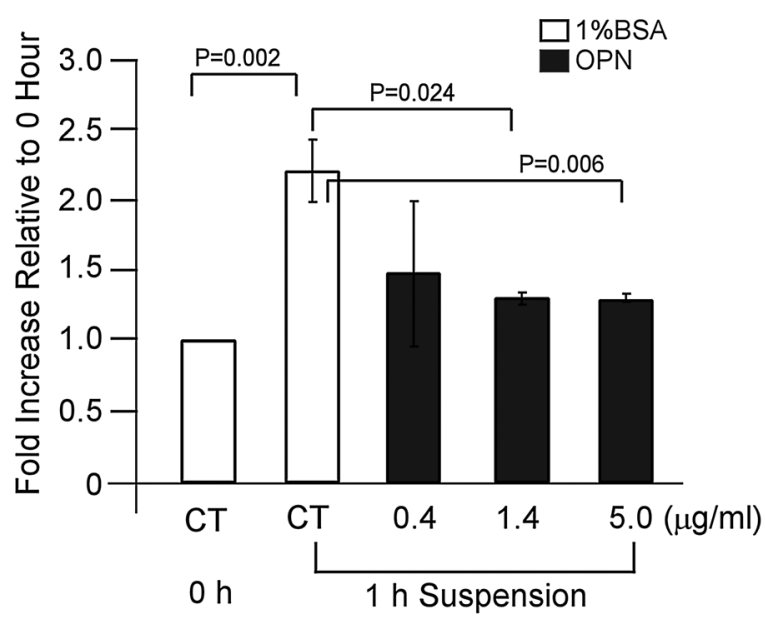

E
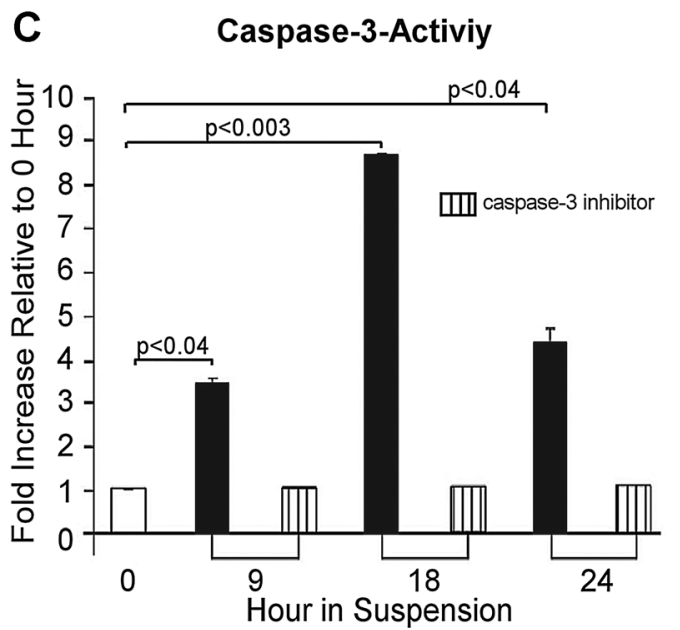

$\square 1 \% \mathrm{BSA} \quad$ Caspase-8 Activity

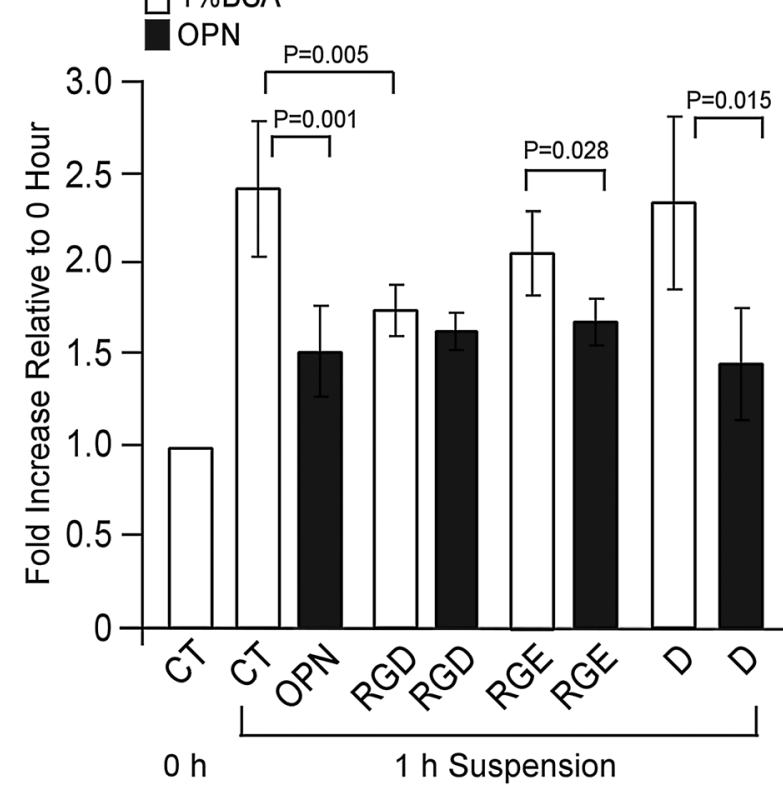

Figure 2. Anoikis of JB6 cells activates caspase- $8,-9$ and -3 , which is suppressed by rOPN, mediated through its RGD-cell binding domain to inhibit caspase-8 activity. (A) JB6 cells suspended in agar were analyzed for caspase- 8 using the addition of its substrate after $0,1,3$, 8 , and $15 \mathrm{~h}$ of incubation, $n=3$ to $8 /$ time point. (B) Caspase- 9 activity analyzed using the ApoAlert Caspase Profiling Plate on cells treated as in $A, n=3 /$ time point. (C) Caspase-3 activity was analyzed using the ApoAlert Caspase Profiling Plate with or without its inhibitor $(10 \mu \mathrm{M})$ in cells suspended on agar at $0,9,18$, and $24 h, n=2$. Caspase activities are relative to that of $0 \mathrm{~h}$ in suspension. (D) Caspase-8

activities were analyzed after cells were suspended for $1 \mathrm{~h}$ in the presence of $1 \%$ BSA (CT), $0.4,1.4$, or $5 \mu \mathrm{g} / \mathrm{ml}$ of rOPN. Caspase- 8 activities are relative to that at $0 h, n=3$ /treatment. Histogram is representative of 2 repeated experiments. (E) Caspase- 8 activities were determined in suspended cells incubated with $1.4 \mu \mathrm{g} / \mathrm{ml}$ of rOPN, or $1 \%$ BSA with or without $1 \mu \mathrm{M}$ of RGD, $1 \mu \mathrm{M}$ of RGE, or $1 \mu \mathrm{M}$ of $D$ peptide for $1 \mathrm{~h}$. RGD: GRGDSL peptide. RGE: GRGESL peptide. D: DRYLKFRI peptide. Cells treated with 1\% BSA only (CT) served as the negative control. Caspase- 8 activities are relative to that at $0 \mathrm{~h}$ ( $n=4-5$ /treatment). 
A

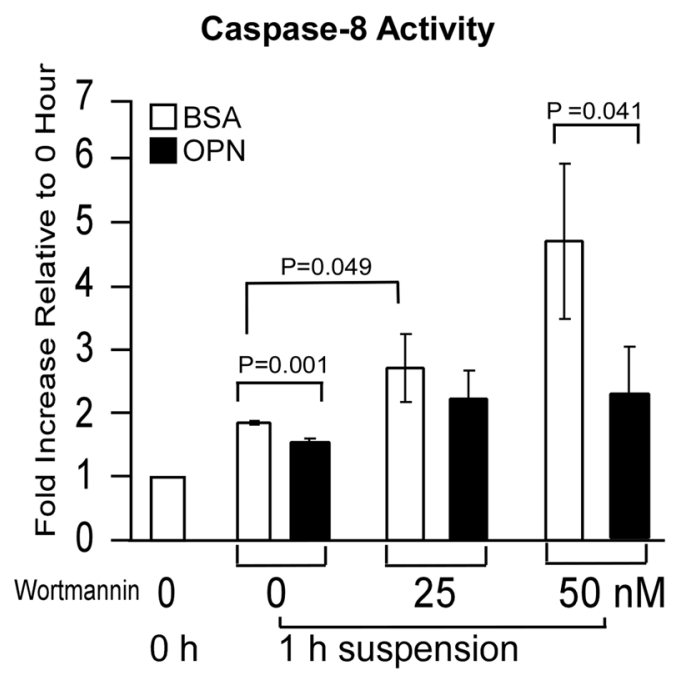

D

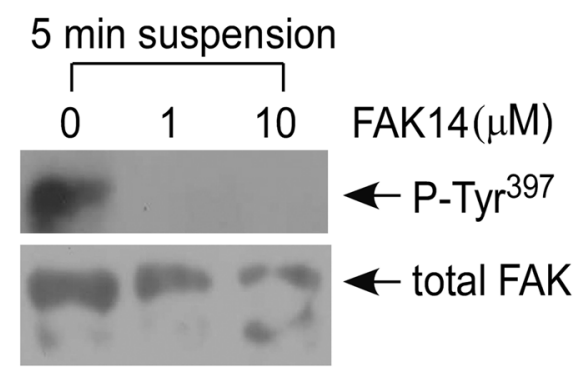

B

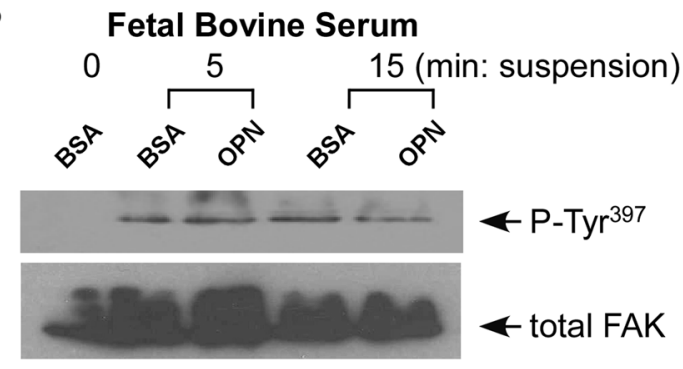

C

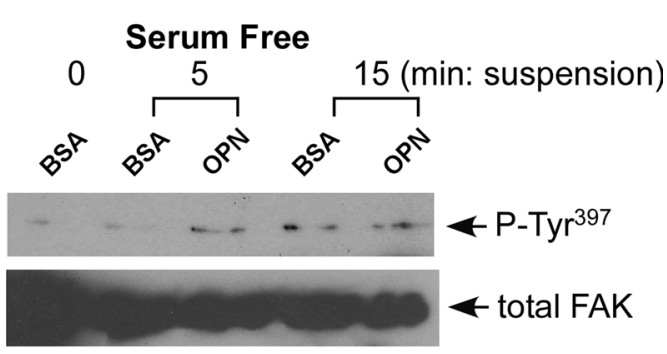

E

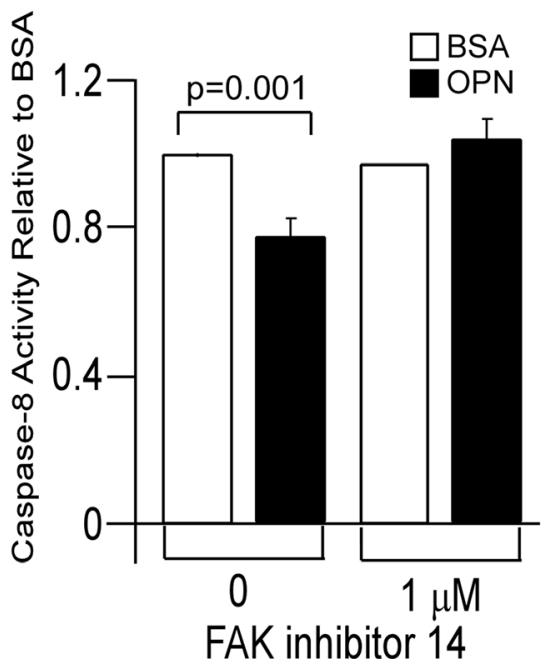

medium containing only $1 \%$ BSA, they were rinsed with PBS after trypsinization. Cell lysates $(800 \mu \mathrm{g})$ were immunoprecipitated with antibody to total FAK and probed with anti-FAK phosphorylatedTyr397 $\left(\mathrm{P}-\mathrm{Tyr}^{397}\right)$. Film exposure times were $10 \mathrm{~min}$ for top panel and $\sim 5-8 \mathrm{~s}$ for lower panel. (D) Western blot analyses of FAK phosphorylation at $\mathrm{Tyr}^{397}$ of suspended cells in serum containing medium treated with FAK inhibitor 14 . Cell lysates $(800 \mu \mathrm{g})$ were treated as described in (B). For blots probed with anti-P-Tyr ${ }^{397}$, film exposure time is $\sim 5 \mathrm{~s}$ and for blots probed with total anti-FAK, film exposure time is $\sim 10 \mathrm{~min}$. (E) Caspase-8 activity was analyzed after the suspending cells were incubated with $1 \mu \mathrm{M}$ of FAK inhibitor 14 in the presence of $1 \%$ BSA or $1.4 \mu \mathrm{g} / \mathrm{ml}$ of rOPN for $1 \mathrm{~h}, \mathrm{n}=3$ /treatment. Caspase- 8 activity of cells treated with OPN was normalized to that of cells treated with $1 \%$ BSA.

which inhibits the autophosphorylation of FAK at $\mathrm{Tyr}^{397}$, prevents OPN suppression of caspase- 8 activity.

To determine if OPN stimulates FAK activation or the autophosphorylation of FAK at Tyr ${ }^{397}$, suspended 
cells in the presence of serum were treated with $1 \%$ BSA or rOPN and harvested after 0,5 , and $15 \mathrm{~min}$ of suspension. Cells at 0 time point, immediately after trypsinization, showed no activation of FAK. However, after 5 and 15 min of suspending cells on agar we observed FAK autophosphorylation at $\mathrm{Tyr}^{397}$ and the addition of rOPN did not further increase the level of FAK activation compared to BSA-treated cells (Figure 3B). This data suggest two possibilities, (1) suspending cells on agar activates FAK to autophosphorylate, or (2) serum in the medium activates FAK.

To address these possibilities, we repeated the overagar assay in serum-free medium with only $1 \%$ BSA. Without serum, cells suspended in BSA showed minimal or no FAK activation at 0 time point or after $5 \mathrm{~min}$, but an increase of FAK activation at $15 \mathrm{~min}$, which could be due to residual serum resulting in minimal activation of FAK. FAK activation is likely not due to the physical suspension of cells, because if it is, then we should observe FAK activation by $5 \mathrm{~min}$ in BSA only medium. In contrast to BSA-treated cells, rOPN stimulated FAK activation by $5 \mathrm{~min}$ of cell suspension, which persisted at 15 min, Figure 3C. This indicates that when cells are suspended without serum, OPN is required to stimulate the autophosphorylation of FAK at $\mathrm{Tyr}^{397}$. In the presence of serum, cells are likely interacting with existing integrin binding matrix proteins such as FN and VN consisting of RGD-cell binding motifs [37], and consequently, FAK activation was observed by $5 \mathrm{~min}$ in the presence of BSA only (Figure 3B), but with the addition of rOPN, the FAK activation persists since there are three potential integrin-binding proteins available. Our conclusion is further supported by previous studies indicating that in serum-free condition, suspended mouse keratinocytes and SP1 cells showed no activation or autophosphorylation of FAK $[38,39]$. Instead, the addition of FN-coated beads to suspended SP1 cells stimulated autophosphorylation of FAK at $\mathrm{Tyr}^{397}$ and $\mathrm{Tyr}^{577}$ [39].

To determine whether inhibiting autophosphorylation of FAK at $\mathrm{Tyr}^{397}$ using FAK inhibitor 14 prevents the OPN suppression of caspase-8 activity, we first evaluated the effect of this inhibitor in suppressing the phosphorylation of FAK at $\mathrm{Tyr}^{397}$ in suspended JB6 cells in the presence of serum. Adherent cells pretreated with FAK inhibitor 14 for $1 \mathrm{~h}$ at concentrations of 1 or $10 \mu \mathrm{M}$ followed by cell suspension for $5 \mathrm{~min}$ resulted in suppressed autophosphorylation of FAK at $\mathrm{Tyr}^{397}$ (Figure 3D). These doses of FAK inhibitor 14 used also showed similar effects in a breast cancer cell line [40]. However, unlike cancer cells, we also observed that by $1 \mathrm{~h}$ treatment with 10 and $100 \mu \mathrm{M}$ of the FAK inhibitor, the viability of adherent JB6 cells were significantly reduced compared to those cells treated with control and $1 \mu \mathrm{M}$ (data not shown). Therefore, only $1 \mu \mathrm{M}$ of FAK14 inhibitor was used in the presence of rOPN for suspended JB6 cells to determine if it prevents OPN suppression of caspase- 8 activation. The results showed that, by preventing the autophosphorylation of FAK at Tyr ${ }^{397}$, rOPN was not able to suppress caspase- 8 activity (Figure 3E). Therefore, FAK activation is necessary and mediates OPN suppression of anoikis, likely through phosphorylation of alternative site(s) of FAK, since cells suspended in serum with BSA already induced autophosphorylation of FAK at Tyr ${ }^{397}$ (Figure 3B).

OPN Stimulates the Phosphorylation of FAK at Tyr ${ }^{861}$ in Suspended JB6 Cells

Besides the autophosphorylation of FAK at Tyr ${ }^{397-}$ additional FAK phosphorylations at $\mathrm{Tyr}^{861}$ have been implicated to be required for mediating cell survival of adherent endothelial cells in response to vascular endothelial growth factor and cancer cells in response to hyperosmotic stress $[33,41]$. Here, we determined if, for suspended JB6 cells, OPN stimulates the phosphorylation of FAK at $\mathrm{Tyr}^{861}$. Immunoprecipitation with anti-FAK antibody followed by Western blot analyses using antibody specific for FAK phospho-Tyr ${ }^{861}$ showed that, in cells suspended for 0 , 5 and $15 \mathrm{~min}$, rOPN stimulates phosphorylation of Tyr $^{861}$ by 5 and 15 min of cell suspension (Figure 4A). The slight increase of FAK phosphorylation at $\mathrm{Tyr}^{861}$ in BSA after $15 \mathrm{~min}$ of cell suspension is likely due to $\mathrm{FN}$ or $\mathrm{VN}$ in serum, since $\mathrm{FN}$ have been shown to increase phosphorylation at $\mathrm{Tyr}^{861}$ of adherent cancer cells [42].

Additionally, the inhibition of autophosphorylation of FAK at Tyr $^{397}$ by FAK inhibitor 14 also inhibited the phosphorylation of FAK at $\mathrm{Tyr}^{861}$ even in the presence of $\mathrm{rOPN}$, indicating that autophosphorylation of FAK at $\mathrm{Tyr}^{397}$ is required, prior to OPN-induced phosphorylation of FAK at $\operatorname{Tyr}^{861}$, Figure 4B. Since FAK inhibitor 14 also inhibited the suppression of caspase- 8 activity by rOPN, Figure 3E, these findings indicate that attenuation of anoikis by rOPN is mediated through FAK phosphorylation at $\mathrm{Tyr}^{861}$.

OPN Suppression of Caspase-8 Activation Is Mediated through FAK Phosphorylation at Tyr ${ }^{861}$

To further confirm that OPN suppression of caspase- 8 activity is mediated through the phosphorylation of FAK at Tyr ${ }^{861}$, cells were transfected with control vector or vectors expressing wild-type FAK or mutant FAKs where Tyr $^{861}$ is mutated to Phe ${ }^{861}$ (FAKY861F) or $\mathrm{Tyr}^{925}$ is mutated to $\mathrm{Phe}^{925}$ (FAK-Y925F) abolishing phosphorylation at these residues. Mutant FAK-Y925F was included, because its phosphorylation at 925 has been reported to occur in an adhesionindependent manner [43]. Caspase- 8 activities of suspended JB6 cells expressing various forms of FAK in the presence of rOPN or BSA were measured. Cells over-expressing FAK had lower caspase-8 activity relative to values for cells with the vector control, and addition of OPN did not further decrease its activity (Figure 4C). Unlike most cancer cells, the 
A
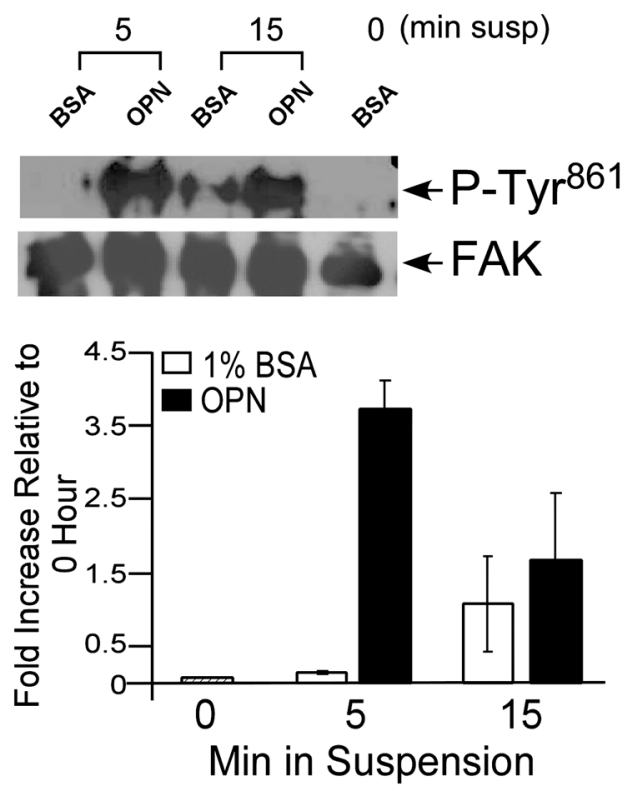

C

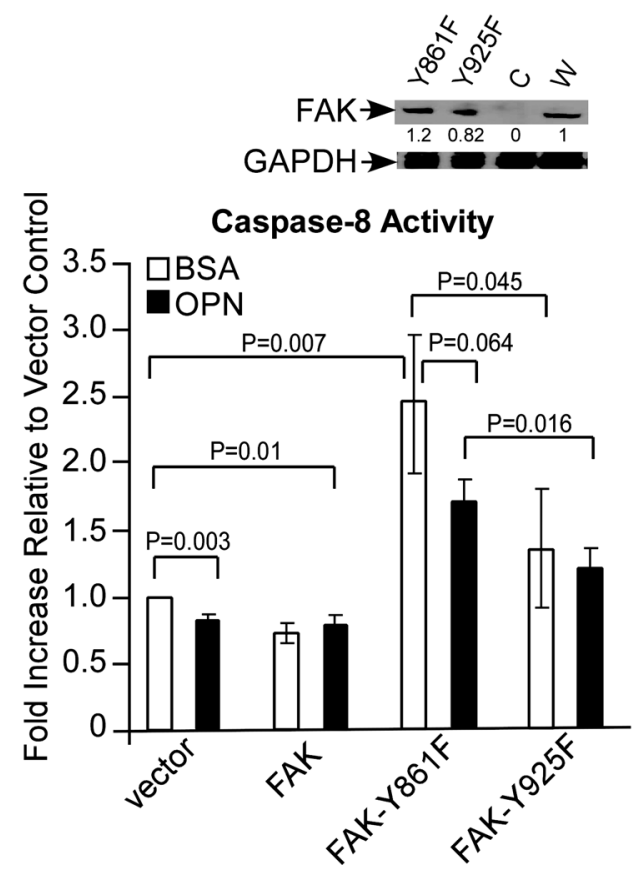

Figure 4. OPN stimulates FAK phosphorylation at $\mathrm{Tyr}^{861}$, which mediates suppression of caspase-8 activity to enhance survival of suspended JB6 cells. (A) Western blot and densitometric analyses of FAK phosphorylation at Tyr ${ }^{861}$. Cells were suspended with rOPN (OPN) or $1 \%$ BSA in growth media for 0,5 , or 15 min on agar. Cell lysates (1 mg) were immunoprecipitated with antibody for total FAK and probed with anti-FAK phospho-Tyr ${ }^{861}\left(\mathrm{P}-\mathrm{T}_{\mathrm{T}} \mathrm{C}^{861}\right)$, followed by antibody for total FAK, film exposure times were $5 \mathrm{~s}$. Lower panel is a histogram of densitometric analyses from Western blot analyses, $n=3$ /treatment. (B) Western blot analyses of FAK phosphorylation at $\mathrm{Tyr}^{861}$ of suspended cells in serum containing medium treated with FAK inhibitor 14 and OPN. Cell lysates $(800 \mu \mathrm{g})$ were immunoprecipitated with anti-total FAK antibody and treated as above, film exposure time is $\sim 10$ min (top panel) and $\sim 5-10$ s (lower panel). (C) Caspase-8 activity of suspended cells transfected wild-type FAK and mutant FAKs. Top
B

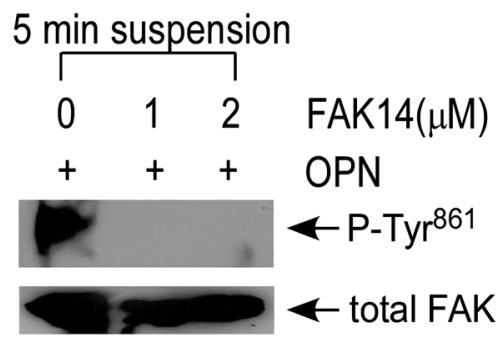

D

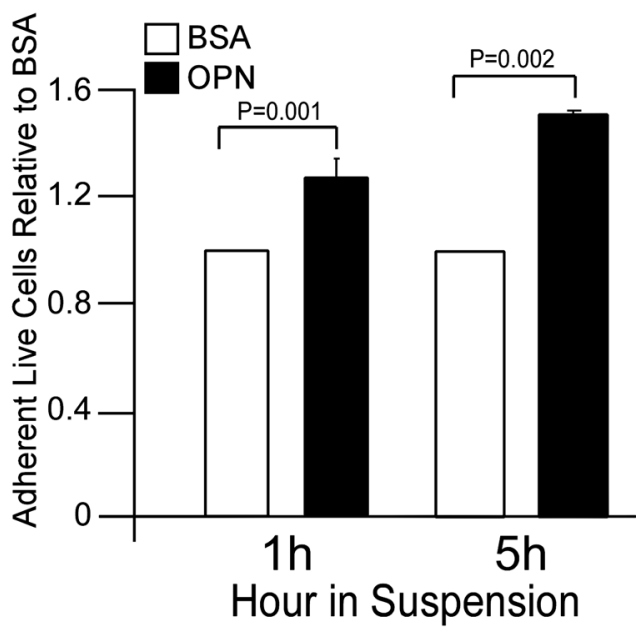

panel, cells were transfected with plasmids of vector only (C), wild-type FAK $(W)$, mutant FAK-Y861F (Y861F), or mutant FAK-Y925F (Y925F). After $24 \mathrm{~h}$ of incubation, these cells were examined for the expression of FAK and the mutant FAKs by Western blot analysis ( $20 \mu \mathrm{g} / \mathrm{lane})$. Relative amounts of transfected mutant FAK to that of transfected recombinant wild-type FAK are specified below the top film. Lower panel, in parallel dishes, the transfected cells were suspended with $1.4 \mu \mathrm{g} / \mathrm{ml}$ of rOPN or $1 \%$ BSA for $1 \mathrm{~h}$ prior to assay of caspase- 8 activity, $n=3 /$ treatment. Caspase-8 activity from cells transfected with vector only and treated with $1 \%$ BSA was set to 1 , and all the other caspase- 8 activities were normalized to vector control. (D) Histogram of live cells after 1 and $5 \mathrm{~h}$ of suspension followed by re-plating on tissue culture dishes for $10 \mathrm{~h}$. Adherent cells were trypsinized and counted by hemocytometer, $n=3 /$ treatment. Data are representative of two to three independent experiments. 
preneoplastic JB6 cells normally express low levels of FAK. Therefore, consistent with other studies on overexpression of FAK $[32,44,45]$, we expected JB6 cells to gain resistance to anoikis and have lower caspase- 8 activation.

Cells expressing excess mutant FAK-Y861F in BSA showed increased caspase- 8 activity relative to cells expressing vector control or wild-type FAK (Figure 4C). Further, the addition of rOPN showed no inhibition of caspase- 8 activity, because the mutated site at 861 of FAK does not allow OPNinduced phosphorylation at 861. Our data clearly indicate that OPN phosphorylation of $\mathrm{Tyr}^{861}$ is necessary to decrease caspase- 8 activity and promote cell survival.

In contrast to cells with mutant FAK-Y861F, cells expressing mutated FAK-Y925F in BSA did not significantly increase caspase- 8 activity relative to cells transfected with the vector control and treated with BSA $(P=0.1)$. However, overexpression of FAKY925F abrogated the ability of OPN to suppress caspase- 8 activity. This suggests that suppression of caspase- 8 activation by rOPN may in part be regulated through the phosphorylation of FAK at $\mathrm{Tyr}^{925}$. Additional studies on whether OPN stimulated phosphorylation of FAK at $\mathrm{Tyr}^{925}$ by Western blot analyses were inconclusive due to lack of antibody specificity. Thus far, our results support a function of OPN in suppressing caspase- 8 activity, which is, at least in part, mediated through phosphorylation of FAK at Tyr $^{861}$.

Addition of OPN to Suspended JB6 Cells Results in Greater Numbers of Cells Surviving When They Are Re-Plated Onto Tissue Culture Dishes

The results above support the concept that OPN is involved in delaying anoikis through activation of FAK at Tyr ${ }^{861}$ and in suppressing caspase-8 activity. To test the capacity of OPN for prolonging the survival of these cells in suspension, we determined if suspended JB6 cells incubated with OPN have an advantage over non-treated cells in attaching and surviving when they are re-plated on tissue culture dishes. This was indeed the case, since after adding rOPN to suspended cells for 1 or $5 \mathrm{~h}$, there were more attached cells on the plates relative those incubated with BSA only (Figure 4D).

\section{DISCUSSION}

Our studies demonstrate that the mechanism by which induced OPN facilitates tumorigenic transformation of preneoplastic epidermal-like JB6 cells is not by stimulating cell proliferation, but rather by suppressing apoptosis. Adherent JB6 cells treated with soluble rOPN exhibit similar cell proliferation assessed by (i) direct cell counting, (ii) analysis of the number of cells at selected cell cycle stage (set by DNA level), and (iii) cyclin D1 expression as cells treated with control. This finding is consistent with our previous observation that suppression of TPA-induced OPN expression and secretion by stably transfecting JB6 cells with antisense OPN does not significantly attenuate JB6 cell proliferation compared with JB6 cells transfected with vector control [17].

Using the over-agar assay to mimic early time points of soft-agar assay, soluble rOPN delays/suppresses anoikis of JB6 cells, as indicated by the reduction in surface PS compared with control cells. JB6 cells in suspension exhibit sequential activation of caspases- $8,-9$, and -3 , which peak at 1,3 , and $18 \mathrm{~h}$, respectively; these findings suggest that caspase- 8 is the primary initiator caspase [46] to induce anoikis in JB6 cells. A specific threshold concentration of exogenous rOPN $(1.4 \mu \mathrm{g} / \mathrm{ml})$ is required to significantly suppress caspase- 8 activation of suspended JB6 cells, while a higher concentration of rOPN shows no additional suppression, suggesting that the effect of OPN is receptor mediated. Indeed, suppression of caspase- 8 activation by OPN is likely mediated through interaction with integrins and not the CD44 receptors, because peptides with its RGD-cell binding motif that bind integrins, but not its DRYLKFRI-cell binding motif, like OPN, suppress caspase- 8 activity. Our attempt to determine which integrins mediate OPN suppression of caspase-8 activity was not successful; this may be because our assays were performed with soluble rOPN in suspended JB6 cells as opposed OPN-coated plates for adherent cells [22].

Liganded integrin receptor potentially signals through the PI3 kinase pathway and/or the FAK pathway to enhance cell survival. Our result using PI3 kinase inhibitor, wortmannin, indicates that the observed suppression of caspase- 8 activity by rOPN is not mediated through PI3 kinase, but rather through activation of FAK, requiring the autophosphorylation of FAK at $\mathrm{Tyr}^{397}$ followed by specific phosphorylation at $\mathrm{Tyr}^{861}$ and possibly, at $\mathrm{Tyr}^{925}$. In the presence of serum, rOPN stimulates the phosphorylation of FAK at $\mathrm{Tyr}^{861}$ and participates with other matrix proteins ( $\mathrm{FN}$ and $\mathrm{VN}$ ) in the serum to activate FAK autophosphorylation at $\mathrm{Tyr}^{397}$ of suspended JB6 cells. FAK inhibitor 14, which inhibits autophosphorylation of FAK at $\mathrm{Tyr}^{397}$, abrogates rOPN-induced phosphorylation of FAK at $\mathrm{Tyr}^{861}$ and rOPN suppression of caspase-8 activity, indicating that autophosphorylation of FAK at $\mathrm{Tyr}^{379}$ is required prior to phosphorylation of at $\mathrm{Tyr}^{861}$ by rOPN to suppress caspase- 8 activity. Transfection assays with mutant FAK-Y861F further confirmed the requirement of phosphorylation of FAK at $\mathrm{Tyr}^{861}$ by OPN to suppress caspase- 8 activity, because the removal of the phosphorylation site at $\mathrm{Tyr}^{861}$ abrogated the ability of OPN to inhibit caspase-8 activity. There is also the possibility that suppression of caspase- 8 activity by OPN is mediated through the phosphorylation of FAK at $\mathrm{Tyr}^{925}$, as cells transfected 
with mutant FAK-Y925F also did not exhibit a reduction in caspase- 8 activity in the presence of rOPN. Our Western blot analysis of phosphorylated FAK at Tyr $^{925}$ by OPN was inconclusive due to the lack of antibody specificity. Our studies, collectively, suggest that in prevention of anoikis of epidermallike pre-neoplastic JB6 cells, OPN can stimulate autophosphorylation of FAK at $\mathrm{Tyr}^{397}$ (if in serumfree media) and, followed by FAK phosphorylation at 861 and possibly, at 925 in suppressing caspase-8 activities to enhance cell survival. Analogous to our findings with suspended pre-neoplastic JB6 cells, OPN promotes the survival of adherent cancer cells overexpressing OPN in hypoxia plus serum-starved conditions, and that OPN's effect is mediated through activation of FAK at Tyr397 requiring its RGD motif [47].

FAK consists of four distinct domains: the N-terminal four-point-one, ezrin, radixin, moesin (FERM) domain, a catalytic kinase domain, two proline-rich domains, and a C-terminal focal adhesion targeting (FAT) domain. The general consensus of an inactive FAK is that the FERM domain interacts with the kinase domain. Engagement of ligands (matrix proteins or growth factors) with integrins or growth factor receptors triggers autophosphorylation of FAK at $\mathrm{Tyr}^{397}$, resulting in a conformational change allowing the docking of Src and subsequent phosphorylation of the tyrosine residues in the kinase domain to activate FAK $[35,48]$. The docking of Src or its activation results not only in phosphorylation of the catalytic kinase domain of FAK, but also in phosphorylation of the residues, $\mathrm{Tyr}^{861}$ and $\mathrm{Tyr}^{925}$ [33,49-51]. Whether Src mediates OPN stimulation of phosphorylation of FAK at $\mathrm{Tyr}^{861}$ and/or at $\mathrm{Tyr}^{925}$ in preventing anoikis remains to be determined.

The present study resolves the question regarding the mechanism by which induced OPN facilitates TPA-induced tumorigenic transformation or colony formation of pre-neoplastic epidermal-like JB6 cells in soft-agar [17], Figure 5. By using excess exogenous OPN to mimic TPA-induced OPN expression, we found that OPN, through its RGD motif interacts with integrins, resulting in phosphorylation of FAK at $\mathrm{Tyr}^{861}$ to suppress caspase- 8 activity and thereby, delays anoikis. In the presence of TPA, it stimulates suspended JB6 cell to secrete a 4-fold increase of OPN over that of control cells. Secreted OPN acts as an autocrine factor in promoting cell survival, and facilitates cell transformation in soft-agar. Soft-agar assays are performed in the presence of serum containing both FN and VN. Furthermore, in the presence of tumor promoter, TPA can also stimulate FN synthesis, but TPA-treated JB6 cells show reduced adhesion to $\mathrm{FN}$ and $\mathrm{VN}$ by $45 \%$ and $55 \%$, respectively, relative to control cells, while a marked increase attachment to OPN (28-fold compared to control cells) is observed [22]. Therefore, TPA-treated cells in

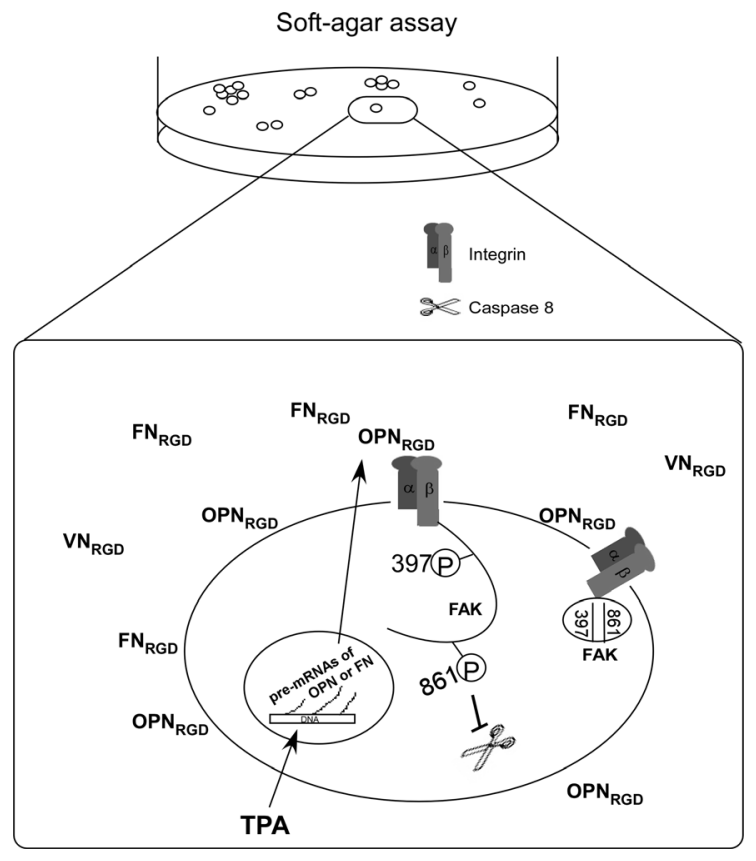

Figure 5. Hypothetical model of OPN facilitating tumorigenic transformation of JB6 $\mathrm{Cl} 41.5 \mathrm{a}$ cells by preventing anoikis. JB6 Cl41.5a (JB6) is a preneoplastic epidermal-like cell line used as an in vitro model for late-stage tumor promotion. TPA stimulates colony formation or tumorigenic transformation of JB6 cells and concomitantly induces the synthesis and secretion of OPN $[18,19]$. We postulate that TPA induces a fourfold increase of OPN secreted by cells (Table 1) embedded in soft-agar and that OPN resides close to the cell surfaces of the cells. Soft agar assays are performed in the presence serum containing both FN and VN and furthermore, TPA may also induce FN secretion [17], thus JB6 cells embedded in soft-agar can also interact with these matrix proteins. However, TPA-treated JB6 cells show reduced adhesion to $\mathrm{FN}$ and $\mathrm{VN}$ by $45 \%$ and $55 \%$, respectively, relative to control cells, while a marked increase attachment to OPN (28-fold compared to control cells) is observed [22]. Therefore, TPA-treated cells in soft-agar likely have a greater preference for OPN compared to FN and VN, supporting our previous observation that down-regulation of OPN compromises TPA-induced colony formation [17]. Base on overagar assay, by use of exogenous OPN to mimic TPA-induced OPN expression, we conclude that OPN, through its RGD motif, specifically phosphorylates FAK at Tyr $r^{861}$ to suppress caspase-8 activity and thereby, delays anoikis facilitating tumorigenic transformation of JB6 cells. OPN $N_{R G D}$, osteopontin synthesized by JB6 cells; FN $N_{R G D}$, fibronectin synthesized by JB6 cells and from serum; $V N_{R G D}$, vitronectin in serum; synthesized by JB6 cells and from serum; $V_{R G D}$, vitronectin in serum;
FAK, focal adhesion kinase; 397 , phosphorylation of FAK at Tyr ${ }^{397} ; 861$, phosphorylation of FAK at Tyr ${ }^{86}$ ?

soft-agar likely have a greater preference for OPN compared to FN and VN, supporting our previous observation that down-regulation of OPN compromises TPA-induced colony formation [17].

This study is significant as it has broad implication for epithelial tissues that normally do not express OPN, but when induced by external or internal factors may facilitate the survival of initiated cells and allowing them to remain dormant prior to transforming into benign and/or malignant cells. Evidence from our in two-stage chemically-induced skin carcinogenesis study also supports the presence of induced OPN in protecting basal normal and initiated keratinocytes [1]. In adult skin, OPN is minimally expressed like that of epidermal JB6 cells. Upon 
treatment with the carcinogen, 7, 12-dimethylbenz (a)anthracene (DMBA) and/or TPA, OPN is markedly expressed in the epidermis by fourfold and over 20 -fold, respectively. Thus, we postulate that in a recurrent stressed environment, OPN secreted into the epidermal microenvironment, not only protects normal keratinocytes, but also enables carcinogeninduced, initiated keratinocytes to survive for an extended period of time, resulting in increased likelihood of developing more papillomae than would occur in the absence of secreted OPN.

\section{ACKNOWLEDGMENTS}

We thank Enid Keyser for sample analyses, Flow Cytometry Core Facility, RDCC-APCF NIH P30 AR48311. We appreciate Dr. Don Hill for reviewing and editing of the manuscript. We thank Dr. David Schlaepfer for providing the mutant FAK (FAK-Y925F) construct and his constructive comments.

\section{REFERENCES}

1. Hsieh YH, Juliana MM, Hicks PH, et al. Papilloma development is delayed in osteopontin-null mice: Implicating an antiapoptosis role for osteopontin. Cancer Res 2006:66:7119-7127.

2. Denhardt DT, Noda M, O'Regan AW, Pavlin D, Berman JS. Osteopontin as a means to cope with environmental insults: Regulation of inflammation, tissue remodeling, and cell survival. J Clin Invest 2001;107:1055-1061.

3. Scatena M, Liaw L, Giachelli CM. Osteopontin: A multifunctional molecule regulating chronic inflammation and vascular disease. Arterioscler Thromb Vas Biol 2007;27:2302-2309.

4. McKee MD, Pedraza CE, Kaartinen MT. Osteopontin and wound healing in bone. Cells Tissues Organs 2011;194:313319.

5. Wai PY, Kuo PC. Osteopontin: Regulation in tumor metastasis Cancer Met Rev 2008;27:103-118.

6. Rittling SR, Chambers AF. Role of osteopontin in tumour progression. Br J Cancer 2004;90:1877-1881.

7. Chang $\mathrm{PL}$, Hsieh $\mathrm{YH}$. The role of matricellular protein osteopontin in tumorigenesis. Precancerous Conditions Research Trends Hauppauge. NY: Nova Science Publishers, Inc; 2007. pp. 5-34.

8. Colburn NH, Bruegge WF, Bates JR, et al. Correlation of anchorage-independent growth with tumorigenicity of chemically transformed mouse epidermal cells. Cancer Res 1978; 38:624-634.

9. Shin SI, Freedman VH, Risser R, Pollack R. Tumorigenicity of virus-transformed cells in nude mice is correlated specifically with anchorage independent growth in vitro. Proc Natl Acad Sci USA 1975;72:4435-4439

10. Dong Z, Birrer MJ, Watts RG, Matrisian LM, Colburn NH. Blocking of tumor promoter-induced AP-1 activity inhibits induced transformation in JB6 mouse epidermal cells. Proc Natl Acad Sci USA 1994:91:609-613.

11. Jansen AP, Colburn NH, Verma AK. Tumor promoter-induced ornithine decarboxylase gene expression occurs independently of AP-1 activation. Oncogene 1999;18:5806-5813.

12. Yang HS, Jansen AP, Komar AA, et al. The transformation suppressor Pdcd4 is a novel eukaryotic translation initiation factor 4A binding protein that inhibits translation. Mol Cell Biol 2003;23:26-37

13. Young MR, Li JJ, Rincon M, et al. Transgenic mice demonstrate AP-1 (activator protein-1) transactivation is required for tumor promotion. Proc Natl Acad Sci USA 1999;96:9827-9832.

14. O'Brien TG, Megosh LC, Gilliard G, Soler AP. Ornithine decarboxylase overexpression is a sufficient condition for tumor promotion in mouse skin. Cancer Res 1997;57:26302637.

15. Halmekyto M, Syrjanen K, Janne J, Alhonen L. Enhanced papilloma formation in response to skin tumor promotion in transgenic mice overexpressing the human ornithine decarboxylase gene. Biochem Biophys Res Commun 1992;187: 493-497.

16. Schmid $T$, Jansen AP, Baker AR, Hegamyer $G$, Hagan JP, Colburn NH. Translation inhibitor Pdcd4 is targeted for degradation during tumor promotion. Cancer Res 2008;68: 1254-1260.

17. Chang $\mathrm{PL}, \mathrm{C}$ ao $\mathrm{M}$, Hicks $\mathrm{P}$. Osteopontin induction is required for tumor promoter-induced transformation of preneoplastic mouse cells. Carcinogenesis 2003;24:1749-1758.

18. Smith JH, Denhardt DT. Molecular cloning of a tumor promoter-inducible mRNA found in JB6 mouse epidermal cells: Induction is stable at high, but not at low, cell densities. J Cell Biochem 1987;34:13-22.

19. Chang PL, Tucker MA, Hicks PH, Prince CW. Novel protein kinase $C$ isoforms and mitogen-activated kinase kinase mediate phorbol ester-induced osteopontin expression. Int J Biochem Cell Biol 2002;34:1142-1151.

20. Chang PL. Prince CW. 1 alpha,25-dihydroxyvitamin D3 stimulates synthesis and secretion of nonphosphorylated osteopontin (secreted phosphoprotein 1) in mouse JB6 epidermal cells. Cancer Res 1991;51:2144-2150.

21. Dion LD, Gindhart TD, Colburn NH. Four-day duration of tumor promoter exposure required to transform JB6 promotion-sensitive cells to anchorage independence. Cancer Res 1988;48:7126-7131.

22. Chang PL, Chambers AF. Transforming JB6 cells exhibit enhanced Integrin-mediated adhesion to osteopontin. J Cell Biochem 2000;78:8-23.

23. Dong Z, Cmarik JL, Wendel EJ, Colburn NH. Differential transformation efficiency but not AP-1 induction under anchorage-dependent and -independent conditions. Carcinogenesis 1994;15:1001-1004

24. Colburn NH. Tumor promoter produces anchorage independence in mouse epidermal cells by an induction mechanism. Carcinogenesis 1980;1:951-954.

25. McGarrity GJ, Steiner T, Vanaman V. Detection of mycoplasma infection of cell cultures by DNA fluorochrome staining. In: Tully JG, Razin E, editors. Methods in mycoplasmology. Vol II. New York: Academic Press; 1983. pp. 155-208.

26. Lasa M, Chang PL, Prince CW, Pinna LA. Phosphorylation of osteopontin by Golgi apparatus casein kinase. Biochem Biophys Res Commun 1997:240:602-605.

27. Darzynkiewicz ZaJ G. Current protocols in cytometry. NY: J. Wiley \& Sons; 1997. pp. 7.5.1-7.5.24

28. Cooper LA, Shen TL, Guan JL. Regulation of focal adhesion kinase by its amino-terminal domain through an autoinhibitory interaction. Mol Cell Biol 2003;23:8030-8041.

29. Lim Y, Han I, Jeon J, Park H, Bahk YY, Oh ES. Phosphorylation of focal adhesion kinase at tyrosine 861 is crucial for Ras transformation of fibroblasts. J Biol Chem 2004;279:29060 29065.

30. Schlaepfer DD, Hunter T. Signal transduction from the extracellular matrix-a role for the focal adhesion proteintyrosine kinase FAK. Cell Struct Funct 1996;21:445-450.

31. Chang PL, Prince CW. 1 alpha,25-Dihydroxyvitamin D3 enhances 12-O-tetradecanoylphorbol-13-acetate-induced tumorigenic transformation and osteopontin expression in mouse JB6 epidermal cells. Cancer Res 1993;53:22172220.

32. Zouq NK, Keeble JA, Lindsay J, et al. FAK engages multiple pathways to maintain survival of fibroblasts and epithelia: Differential roles for paxillin and p130Cas. J Cell Sci 2009; 122:357-367.

33. Abu-Ghazaleh R, Kabir J, Jia H, Lobo M, Zachary I. Src mediates stimulation by vascular endothelial growth factor of the phosphorylation of focal adhesion kinase at tyrosine 861, and 
migration and anti-apoptosis in endothelial cells. Biochem J 2001;360:255-264.

34. Lin YH, Yang-Yen HF. The osteopontin-CD44 survival signal involves activation of the phosphatidylinositol 3-kinase/Akt signaling pathway. J Biol Chem 2001;276:46024-46030.

35. Frame MC, Patel H, Serrels B, Lietha D, Eck MJ. The FERM domain: Organizing the structure and function of FAK. Nat Rev Mol Cell Biol 2010;11:802-814.

36. Frisch SM, Ruoslahti E. Integrins and anoikis. Curr Opin Cell Biol 1997:9:701-706

37. Hayman EG, Pierschbacher MD, Suzuki S, Ruoslahti E. Vitronectin-A major cell attachment-promoting protein in fetal bovine serum. Exp Cell Res 1985;160:245-258.

38. Manohar A, Shome SG, Lamar J, et al. Alpha 3 beta 1 integrin promotes keratinocyte cell survival through activation of a MEK/ERK signaling pathway. J Cell Sci 2004;117:40434054.

39. Lin EH, Hui AY, Meens JA, Tremblay EA, Schaefer E, Elliott BE. Disruption of $\mathrm{Ca}^{2+}$-dependent cell-matrix adhesion enhances c-Src kinase activity, but causes dissociation of the c-Src/FAK complex and dephosphorylation of tyrosine-577 of FAK in carcinoma cells. Exp Cell Res 2004;293:1-13.

40. Golubovskaya VM, Nyberg C, Zheng M, et al. A small molecule inhibitor, 1,2,4,5-benzenetetraamine tetrahydrochloride, targeting the y397 site of focal adhesion kinase decreases tumor growth. J Med Chem 2008;51:7405-7416.

41. Lunn JA, Jacamo R, Rozengurt E. Preferential phosphorylation of focal adhesion kinase tyrosine 861 is critical for mediating an anti-apoptotic response to hyperosmotic stress. J Biol Chem 2007;282:10370-10379.

42. Shi Q, Boettiger D. A novel mode for integrin-mediated signaling: Tethering is required for phosphorylation of FAK Y397. Mol Biol Cell 2003;14:4306-4315.

43. Hauck CR, Hunter T, Schlaepfer DD. The v-Src SH3 domain facilitates a cell adhesion-independent association with focal adhesion kinase. J Biol Chem 2001;276:17653-17662.
44. Kurenova $E, X u L H$, Yang $X$, et al. Focal adhesion kinase suppresses apoptosis by binding to the death domain of receptor-interacting protein. Mol Cell Biol 2004;24:43614371.

45. Tamagiku Y, Sonoda Y, Kunisawa M, et al. Down-regulation of procaspase-8 expression by focal adhesion kinase protects $\mathrm{HL}$ 60 cells from TRAIL-induced apoptosis. Biochem Biophys Res Commun 2004;323:445-452.

46. Nunez G, Benedict MA, Hu Y, Inohara N. Caspases: The proteases of the apoptotic pathway. Oncogene 1998;17 3237-3245.

47. Courter D, Cao H, Kwok S, et al. The RGD domain of human osteopontin promotes tumor growth and metastasis through activation of survival pathways. PLoS ONE 2010;5:e9633.

48. Schaller MD. Cellular functions of FAK kinases: Insight into molecular mechanisms and novel functions. J Cell Sci 2010; 123:1007-1013.

49. Calalb MB, Zhang X, Polte TR, Hanks SK. Focal adhesion kinase tyrosine-861 is a major site of phosphorylation by Src. Biochem Biophys Res Commun 1996;228:662-668.

50. Polte TR, Hanks SK. Complexes of focal adhesion kinase (FAK) and Crk-associated substrate (p130(Cas)) are elevated in cytoskeleton-associated fractions following adhesion and Src transformation. Requirements for Src kinase activity and FAK proline-rich motifs. J Biol Chem 1997;272:5501-5509.

51. Brunton VG, Avizienyte $E$, Fincham VJ, et al. Identification of Src-specific phosphorylation site on focal adhesion kinase: Dissection of the role of Src SH2 and catalytic functions and their consequences for tumor cell behavior. Cancer Res 2005;65:1335-1342.

\section{SUPPORTING INFORMATION}

Additional supporting information may be found in the online version of this article. 